\title{
The Effect of Diversity Management on Organizational Performance: The Case of Ethio-Telecom South West Region
}

\author{
Abdulhakim Mulu and Shimelis Zewdie
}

\section{ABSTRACT}

The aim of this paper is examining the effect of diversity management on organizational performance by focusing on EthioTelecom (Ethiopian Telecommunication) South West region offices. Using Survey research design a quantitative data was randomly collected from a total of $\mathbf{1 2 0}$ employees. Path analysis was conducted to test the three research hypothesis. The result of empirical analysis showed that organizational diversity management constructs or dimensions (ethnicity, gender, and religion) are positively related with organizational performance. Hence, diversity management can positively influence employee productivity, satisfaction, creativity and innovation and better decision making there by fostering organizational performance.

Keywords: Diversity management, Ethnic diversity, Gender diversity, Religious diversity, Organizational performance.

\section{INTRODUCTION}

\section{A. Background of the Study}

In late twentieth and early twenty-first centuries, diversity and multiculturalism as social phenomenon have attracted many attentions in many social sectors: in education, health, government, in the media and workplaces [1]. The diversity which can be represented by the composition of minorities, women, different age groups and the like is increasing both at workplaces and over the world [2], [3]. In this regard, having its root in United State, which is considered as the pioneer of diversity movement, diversity is now echoed across many countries [1]. Due to the increasing of differences in the population of many countries, organizations are focusing on diversity management to become totally inclusive and increase productivity and competitive advantages [4]. In addition, the calls for workplace diversity are either financial necessity or fundamental fairness, equitability, and morality [5]. Further, as [6] stated the two decades researches of 1980s on business cases regarding diversity management and implementation in organizations and at work places evidenced that no more legitimacy and profitability by excluding women or racial and minorities from work places. More specifically, having realized the importance of leveraging diversity, many companies in USA have incorporated diversity trainings in their employee orientations and developments programmes to achieve competitive advantages [7].

From human resource perspective, diversity management is used to attract, retain and effectively manage workplace diversity in order to contribute to organizational performance which can be only achieved by realizing the potential of diverse work forces [8]. For instance, as demographic diversity increases, the cognitive resources and ability also increases in the engagement of complex problem solving and thinking [9]. Further, [10] also stated that successful human diversity management does not stand alone but also integrated component of human resource management system and concluded that companies which manage diversity issues demonstrate higher level of business performance. Similarly, [11] in their empirical review related with human resource management and diversity management, stated the existence of the relationship between demographic representation of employees and human resource management practices such as employee development and promotions, hence, result in individual, group and organizational outcomes. For further confirmation, the finding by [3] suggested that human resource managers should enact workplace diversity management programs and create better understanding how diversity functions in an organization.

More specifically, effective diversity management requires recognition of communalities which further explained by emotional, solidarity, legal and political recognitions and awareness of differences at workplaces or in an organization [7], [12]. Contrarily, [13] stated that manifestations such as inaccurate stereotypes and prejudices are the barriers and challenges of effective diversity management which finally result in scarification of competence and quality. Hence, effective diversity management requires work climate assessment, diversity initiatives and training programmes [14]. It also requires individual assessment and treatment which is presumably irrespective of discrimination or favouritism [1]. For instances, employees more benefited from diversity initiatives when the workplace is inclusive than when they are discriminated or stigmatized [15]. Though 
the subject of diversity and its workplace management has been extensively studied especially in western literature, the issue has drawn little attention in academic circle and research community nationally. In other words, empirical studies on diversity management, particularly its effect on organizational performance on Ethiopian firms are lacking. [16] Suggested that many researches on diversity management should be tested for practical reasons at different work places and organizational settings. To this end, empirical investigation on the issue related to diversity management on local governmental organization is important as it enriches and adds Ethiopian perspective to the exiting literature.

\section{B. Statement of the Problem}

Creating work environment that supports and values workplace diversity is important for organization to make the best out employees because employees in such environment can feel included, their ideas, opinions and suggestions are well come, and these can result in positive organizational outcomes. Diversity management at workplaces positively affects organizational performance which results from organizational pooled talents and better decision making [17]. Work place diversity management is also resulted in organizational competitive advantages which can benefit organizations in terms of recruiting and retaining talents, improving quality, productivity, efficiency, creativity and satisfaction, customer services and reduction of work place discriminations and harassments [18]-[20] and [2].Studies made by [21] and [22] showed the relationship between diversity dimensions such as gender, religion and ethnicity(race) and organizational performances including employee satisfaction, turn over and productivity.

However, many previous studies were limited to private organizations [20]. Furthermore, previously, many diversity studies on diversity more focused on social identities and recent workplace development requires specific organizational context of workplace diversities [6]. Particularly, empirical researches on how demographic diversity affects both financial and non-financial organizational performance are limited [23]. Many companies across the world have encountering difficulties in harnessing the positive effect of employing diverse work forces [10]. The same is true when it comes to Ethiopia. Knowledge regarding diversity management is at infancy stage, more importantly diversity management and its positive effect on organizational performance has little studied.

Therefore, the purpose of this paper is to examine and test demographic diversity ethnicity, gender, and religion on employee work performance at Ethio-telecom. Hence three constructs or independent variables (gender, religion, and ethnicity) were tested against one dependent variable i.e., organizational performance using path analysis model. The test showed the impact of constructs and measurement scales of organizational workplace diversities on the organizational performance which explained in employee productivity, satisfaction, less turn over, creativity and innovation, better decision-making, the quality of services and products, better management and leadership, corporate culture and reputation and team performance. Resource based view was used to explain the outcome of the study especially the positive effect of workplace diversity on employee performance.

\section{Objective of the Study \\ 1. General objective}

The main objective of this study is to examine the impact of demographic diversity: ethnicity, gender, and religion on employee work performance at ethio-telecom South West region.

\section{Specific objectives}

- Examine the underlying relationship between ethnic diversity and organizational performance.

- Identify the association between gender diversity and organizational performance.

- Test the relation between religious diversity and organizational performance.

\section{LITERATURE REVIEW AND HYPOTHESIS}

In the beginning 21 st century, due to globalization effects, cross-border trade and investments has become global village day to day interactions because of advances in transportation and telecommunication technologies [22]. Hence, business comes to be cut throat competitions and many companies need to employee diverse work forces in order to survive in such competitive business environment and diversity at work place has become the central issue of the contemporary organizations [22], [20]. Many researchers and scholars have defined diversity from different perspectives. I also refined the definitions given by these scholars to develop this paper conceptual framework and hypothesis. Accordingly, diversity is defined as the existence of a workforce in which individual employees comes from different, demographic socio-cultural, ethnic and religious backgrounds [23]-[26], [2]. In other words,[13] summarized the definition of work force diversity as the multitude of the individual differences and similarities that exist among people working with in an organization. More precisely, [1] defined diversity as all about differences and inclusions. They also explained diversity management, originated from US and recently more operationalized terms in many countries and organizations, as valuing the differences among people in an organization.

Moreover, many scholars noted that work force diversity leads to positive effect of overall organizational performance [2]. Similarly, substantial literatures also argue that workplace diversity can result in positive organizational performance advantages such as attracting and retaining best talents [4]. [17] and [27] also described the positive relationship between workplace diversity such as racial difference and overall organizational performances. In addition to this, many researchers tried to link diversity representation (racial and gender demographic group proportion in the organization) and organization business performance [9]. Further, through creating inclusive work climate, diversity management can boost positive attitude and behaviours of all employees [8].

Many researchers described workplace diversity as multidimensional as primary and secondary dimensions. The primary dimensions include age, disability, ethnicity, race, and gender whereas secondary dimension embraces culture, sexual orientation, thinking style, religion, lifestyle, 
economic status, education, nationality, geographic origin, political orientation, language, family status and work experience [2], [4], [28]. In addition, [16] also proposed two dimensions of diversity as surface -level diversity attributes which are easily visible consists of age, gender, and race/ethnicity and deep-lever diversity which cannot be immediately and directly observed including personalities, attitudes, beliefs and values, sexual orientation, religious and beliefs. Hence, we can conceptualize the diversity management as multitude of the individual differences and similarities that exist among people working with in an organization which are visible or invisible directly and also positive intention that can be manifested as racial or ethnic, demographic and religious differences and similarities. In the following paragraphs, I tried to explain selected diversity management dimensions such as ethnicity $\neg$, gender and religious affiliation and formulate the hypothesis in relation with organizational performance.

\section{A. Ethnic Diversity}

Ethnic diversity refers to the heterogeneity in mother languages, cultures and races that exists in an organization [23]. According to social identity perspective, ethnicity is one of the demographic attributes in which individuals classify themselves (Joshi \& Liao, 2006). On the other hand, many researchers also stated that workplace ethnic diversity, many of them have used in the same operational definition of racial diversity, affects an organizational performance. For instance, [23] tried to link the effect of ethnicity on organizational performance. Further, [30], in their review of diversity research, tried to criticize the rough treatment of race or ethnicity and appealed to researchers to acknowledge it by taking the case of U.S society and workplace. They also evidenced that the historical salience of some ethnic diversity might be the cause for the dynamics of ethnicity in the organization [29]. Particularly, [20] also stated that organizational ethnic/racial diversity is positively associated with organizational performance. In other words, individuals who are more likely exposed to different ethnic group and more heterogeneous and inclusive settings are less likely to hold stereotype and more accepting dissimilarities and therefore increases attracting and retaining talent workforce [28], [31]. More specifically, [32] stated that ethical diversities are more informative and relevant to the demographic make-up of current work force. Hence, diverse work force in terms of ethnic origin can be used to bridge cultural boundaries and search for original problem solutions, innovative product ideas, and market initiatives and finally result in organizational competitive advantages [12].

Hypothesis 1: Ethnic diversity is positively associated with organizational performance.

\section{B. Gender Diversity}

Gender, which is one of the primary dimensions of diversity, is defined as the psychological disparities and experience that socially or culturally attached to being female or male in an organization [23]. [4] also stated gender diversity has also the most impact on groups in workplace and society. For instance, the research conducted in high-tech industries evidenced that talents generated by gender diversity in an organization becomes priceless advantages which can be explained by better problem solving abilities and dealing with complex issues and less susceptible in group thinking [4]. More precisely, [24] proposed that gender diversity is positively associated with organizational performance. Specifically, [5] stated that gender diversity in organizations board of directors has important implication for organizational performance. Further, [9] reviewed that present research links gender demographic group representation in an organization is the implication for organizational performance and hence companies should encourage employees to take the advantages of their differences and use for greater innovation and problem solving capabilities. For instance, as [28] stated gender diversity in service industry particularly produces positive effect on employee productivity. On the other hand, gender discrimination indicates lack of career advancement in academic medicine and top management and executive position [33]. More generally, higher gender diversity tends to increase organizational performance especially when employee works together for a longer time [20]. Hence, I formulated the following hypothesis as:

\section{Hypothesis 2: Gender diversity is positively associated with organizational performance.}

\section{Religious Diversity}

In the classification written by [2], religion is the secondary dimensions of diversity management at workplace and in organizations while other researchers, [12], stated it as one of the demographic aspects that experienced in many countries. These researchers also reviewed that religious diversity at workplace is also one of the inherent creativities and innovative potential that can result in organizational competitive advantages. However, there are only few countries that have implemented diversity policies that invite employees from different religious backgrounds and hence responsive strategies should be taken to focus on using workers capabilities regardless of their religion background [34]. Further, few researchers tried to relate the impact of religion diversity with organizational performance while others include religion diversity under demographic diversity and limited in explaining the extent that religious diversity has on over all organization performance [23], [12], [20].

Hypothesis 3: Religious diversity is positively associated with organizational performance

\section{Study Model}

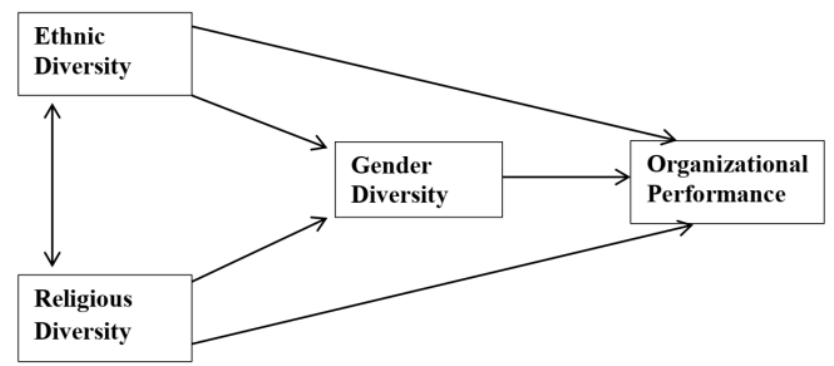

Fig. 1. Model of the study. 


\section{Methods And Results}

\section{A. Research Design, Population and Sample}

Survey research method was employed to obtain quantitative data from target population of the study or subject of the study (employees of Ethio-telecom western region). Sample frame of the study was 172 employees. Yamane's 1967 simplified formula was employed to calculate sample size with $50 \%$ of population proportion, at 95\% degree confidence level and 5 percent margin of errors. Accordingly, 120 employees were computed as a sample and used in the study. The researcher randomly selected these employees from the branches in Jimma Zone.

\section{B. Data Collection Technique and Procedure}

Primary data was collected through questionnaire. Standard survey questions were adopted and modified to suit the context. In relation to organizational performance scale the items reflect attributes such as employee productivity, satisfaction, creativity and innovation and better decision making. The indicators for ethnic diversity and gender diversity were adopted from [2], [4], [8] and [17] with some modifications to show ethnic and gender diversity of the targeted organization. With regard to religious diversity construct items were also adopted from [2], [12] and [20] to estimate the organizational performance.

5-point likert scale was used to measure and estimate all the parameters and their attributes. The Cronbach alpha results of $0.744,0.822$, and 0.755 coefficient were reported for ethnic, gender and religious diversity respectively in many studies. Internal consistencies for all constructs are greater than 0.70 which is recommended by various scholars. Translated versions of Amharic and Afan Oromo accompanied the English version for participants who were unintelligible in English. Path model analysis were used to test the three hypothesis and higher standard beta values used to measure the magnitude of the relationship.

\section{ANALYSIS AND RESUltS}

To check the Common Method bias of all observed items of the survey, the total variance explained was run and the unrotated factor shows the first item result in $47.8 \%$ of the total variance. Therefore, this result suggests that there was no common method bias since the value was not above $50 \%$ [35]. Further, I used convergent validity including factor loading score, average variance extracted (AVE) and discriminant validity to assure the quality of measurement model. Additionally, item's reliability was checked by using reliability coefficient $(\alpha)$ to evaluate the consistency of the measured items of the constructs. The communality value of REL3 was lower and deleted from the set because it was less than the suggested value of thumb rule 0.50 to increase the AVE of the religious diversity indicators. All rotated factor loading values of the items were also significant loading (greater than 0.40 which is recommended in literatures). Additionally, the Cronbach alpha values or CR is greater than the recommended values 0.70 . CR values can be increased by increasing the number items to evaluate the constructs. Further, reliability coefficient value of 0.70 and more are also recommended to be very good in items internal consistency to measure the proposed construct. As a result, except one items of religious diversity (REL3) all items proposed under the three constructs are significant to indicate the structural model. To sum up, factor loading values, AVE and CR reported shows convergent validity of the model holds. Table I shows the overall report.

Further, the discriminant validly of the model was evaluated by comparing the AVE and squared correlation of the three constructs of the model [36]. As it was shown in Table I, the AVE values of ethnic diversity, gender diversity and religious diversity constructs are $0.660,0.680$ and 0.670 while the correlation estimate between them were $0.31,0.43$ and 0.33 respectively. Hence, AVE of the construct were greater than their respective squared correlations and discriminant validity of the items holds.

TABLE I: RESUltS OF MEASUREMENT MODEL

\begin{tabular}{|c|c|c|c|c|c|}
\hline Constructs & $\begin{array}{c}\text { Measurement } \\
\text { variables }\end{array}$ & $\begin{array}{c}\text { Factor } \\
\text { loading }\end{array}$ & Communality & AVE & $\begin{array}{c}\text { Cronbach's } \\
\text { alpha }(\alpha)\end{array}$ \\
\hline \multirow{4}{*}{ Ethnic diversities } & ETH1 & 0.597 & 0.691 & \multirow{4}{*}{0.660} & \multirow{4}{*}{0.744} \\
\hline & ETH2 & 0.603 . & 0.663 & & \\
\hline & ETH3 & 0.795 & 0.731 & & \\
\hline & ETH4 & 0.713 & 0.548 & & \\
\hline \multirow{5}{*}{ Gender diversities } & Gend 1 & 0.567 & 0.539 & \multirow{5}{*}{0.680} & \multirow{5}{*}{0.822} \\
\hline & Gend2 & 0.838 & 0.710 & & \\
\hline & Gend3 & 0.863 & 0.791 & & \\
\hline & Gend4 & 0.674 & 0.773 & & \\
\hline & Gend5 & 0.637 & 0.664 & & \\
\hline \multirow{3}{*}{ Religion diversities } & REL1 & 0.596 & 0.718 & \multirow{4}{*}{0.670} & \multirow{4}{*}{0.755} \\
\hline & REL2 & 0.786 & 0.689 & & \\
\hline & REL4 & 0.712 & 0.659 & & \\
\hline & REL5 & 0.649 & 0.610 & & \\
\hline Organizational & OP1 & 0.782 & 0.829 & \multirow{4}{*}{0.875} & \multirow{4}{*}{0.849} \\
\hline \multirow[t]{3}{*}{ Performance } & OP2 & 0.620 & 0.938 & & \\
\hline & OP3 & 0.734 & 0.792 & & \\
\hline & OP4 & 0.601 & 0.940 & & \\
\hline
\end{tabular}

AVE $=$ Average Variance Extracted, REL3 was deleted (communality value below 0.50).

\section{A. Hypothesis Testing}

Structural Equation Model path analysis was used to test the proposed hypotheses of ethnic diversity, gender diversity and religious diversity. Coefficient of determination $\left(\mathrm{R}^{2}\right)$ and the significance of the path coefficient $(\beta)$ were used to evaluate the structural model. The value of $\mathrm{R}^{2}$ for organizational performance was $57 \%$ which indicates the percentage of organizational performance explained by the three dimensions of diversity management ethnic, gender and religious diversities. 
In this study, three hypotheses were proposed ethnicity, gender and religious diversities as organizational diversity management, positively related with organizational performance. The empirical result of the path analysis showed ethnic diversities are positively related with organizational performance $(\beta=0.26, p<0.01)$. In addition, gender diversity, as one of the three constructs or dimensions of diversity management, also positively related with organizational performance $(\beta=0.46, p<0.01)$. Similarly, the result of the third hypothesis was also showed positive relationship between diversity management and organizational performance $(\beta=0.23, p<0.01)$. Therefore, all hypotheses were strongly significant and supported, Table II.

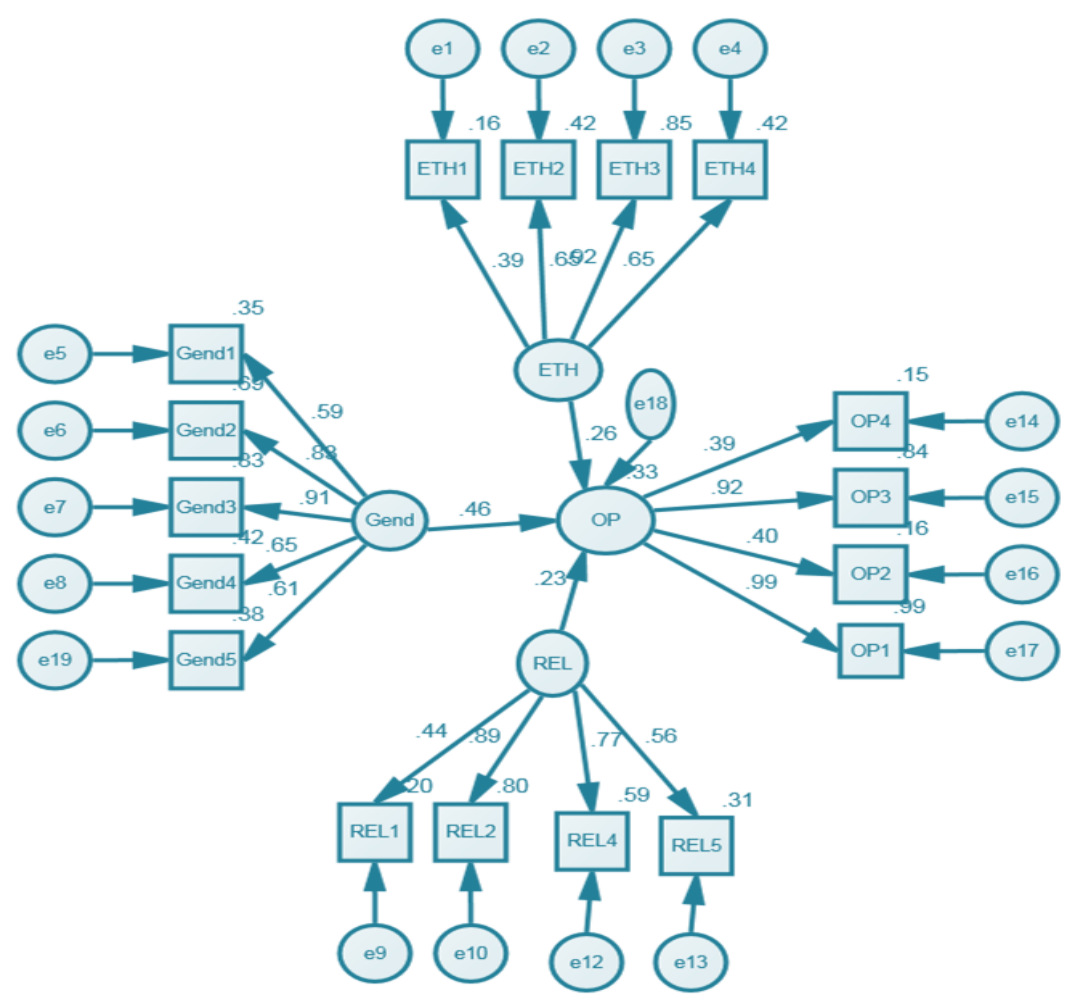

Fig. 2. Structural model.

\begin{tabular}{cccc}
\multicolumn{4}{c}{ TABLE II: RESULT OF PATH ANALYSIS } \\
\hline Hypothesis & Parameter & Beta & Decision \\
\hline H1: ETH $+\rightarrow$ OP & PETH, OP & $0.26^{* *}$ & Supported \\
H2: Gend $+\rightarrow$ OP & PGend, Op & $0.46^{* *}$ & Supported \\
H2: REL $+\rightarrow$ OP & PREL, OP & $0.23^{* *}$ & Supported \\
\hline
\end{tabular}

$* * \mathrm{p}<0.01, \mathrm{ETH}=$ Ethnic, Gend = Gender, REL $=$ Religious, Op $=$ Organizational Performance.

\section{DISCUSSION}

This study tried to investigate the effect of diversity management on organizational performance, specifically, the effect of diversity management dimensions or constructs, in terms of ethnic, gender, and religious diversity by taking some branches of telecom organization in south west Oromia. The result of the path analysis of Structural Equation Modeling (SEM) indicated that all diversity management constructs or dimensions, ethnic, gender and religious diversities are strongly significant and positively related with organizational performance. Previous studies have been also evidenced that diversity management dimensions such as ethnic, gender and religious diversities are positively related with organizational performance explained in terms of employee productivity, satisfaction, creativity and innovation and better decision making [2], [4], [17], [27], [9], [8].

Workplace diversity management produces positive organizational performance and increases employee satisfaction, creativity and innovativeness, productivity and better decision making which result company's competitive advantage [4], [17], [27], [9], [8]. Further, [2] confirmed that diversity management constructs (ethnic or racial, gender and religious) promotes positive employee behaviours and attitude. Similarly, research finding by Cunningham [17] also verified that workplace ethnic or racial diversity management is positively related with over all organizational business performance. Moreover, forms of organization and workplace diversity management such as ethnic or racial and demographic diversities have predictive power of organizational performance outcomes or positive effect [8], [29], [28], [31], [23].

As hypothesized in this paper, the relationship between ethnic, gender and religious diversities and organizational performance were tested to be strongly significant and positive. As a result, a country like Ethiopia, where there are high social diversities such as ethnic and religious diversities exist, organization or workplace diversity management positively influences employee, groups, and organizational performance at different levels. This study result showed the same fact which is also in line with previous scholars' investigation findings regarding diversity management. As a result, many public organization administrators or leaders have to effectively enact diversity management programs such as ethnic diversity training, gender affirmative actions and religious diversity management training programs to boost overall organizational performance. 


\section{CONCLUSION}

This study examined the workplace diversity management (ethnic, gender and religious diversities) effect on organizational performance. The empirical result of this study showed that organizational diversity management (ethnic, gender and religious diversities) positively affects over all organizational performance. Hence, organizational diversity management such as ethnic, gender and religious diversities are the predictors of organizational performance. More specifically, gender diversity management is highly significant and determinant for organizational performance in this context (Ethiopia telecom south west Oromia branches), where many employees with different ethnic and demographic background are working together for a longer time.

\section{MANAGERIAL IMPLICATION}

The key focus of this study was to test how organizational diversity management affects organizational performance by taking different branches of Ethiopian telecom in south west oromia. To test the validity of these diversity management constructs or dimensions, I proposed three hypotheses and tried to collect data from many employees. Finally, the result of this empirical test revealed that organizational diversity management is positively related with organizational performance. Hence, organizational managers who are interested in boosting organizational performance need to consider organization or workplace diversity management. More specifically, in Ethiopian context, employee's ethnic diversity shows the need for managers to invest more efforts on diversity management to increase overall organizational performance.

\section{REFERENCES}

[1] Prasad, P., Pringle, J., \& Konrad, A. (2005). Examining the contours of workplace diversity: Concepts, contexts and challenges.

[2] Makhdoomi, U., \& Nika, F. (2017). Workforce diversity and employee performance-an empirical study of telecom organizations. Amity Global Business Review, 108-115.

[3] Simons, S., \& Rowland, K. (2011). Diversity and its impact on organizational performance: The influence of diversity constructions on expectations and outcomes. Journal of Technology Management \& Innovation, 6(3), ISSN: 0718-2724.

[4] Mazur, B. (2010). Cultural diversity in organisational theory and practice. Journal of Intercultural Management, 2(2), 5-15.

[5] SaintDic, Y. (2014). Modelling diversity management practices in corporate ethics: The spillover effect. Dissertation for the Degree of Doctor of Business Administration, Kennesaw State University.

[6] Kalonaityte, V. (2010). The case of vanishing borders: Theorizing diversity management as internal border control. Organization Articles, 17(1), 31-52, ISSN 1350-5084.

[7] McMahon, A. (2010). Does workplace diversity matter? A survey of empirical studies on diversity and firm performance. Journal of Diversity Management, 5(2), 37-48.

[8] Ashikali, T., \& Groeneveld, S. (2015). Diversity management for all? An empirical analysis of diversity management outcomes across groups. Emerald Personnel Review, 44 (5), 757-780.

[9] Mason, D., \& Aramovich, N. (2013). The psychological benefits of creating an affirming climate for workplace diversity. Group \& Organization Management, 38(6), 659-689.

[10] Armstrong, C., Flood, P., Guthrie, J., Liu, W., Maccurtain, S., \& Mkamwa, T. (2010). The impact of diversity and equality management on firm performance: beyond high performance work systems. Human Resource Management, 49(6), 977-998.

[11] Kossek, E., Lobel, S., \& Brown, J. (2005). Human resource strategies to manage workforce diversity: Examining 'the business case', 54-74.
[12] Pless, N., \& Maak, T. (2004). Building an inclusive diversity culture: Principles, processes and practice. Journal of Business Ethics, 54, 129 147.

[13] Ann, O., \& Ukpere, W. (2014). The effect of workforce diversity on organizational performance of selected firms in Nigeria. Mediterranean Journal of Social Sciences, 5(10), ISSN 2039-2117.

[14] Prieto, L., \& Osiri, J. (2009). Linking workplace diversity to organizational performance: A conceptual framework. Journal of Diversity Management, 4(4), 13-22.

[15] Joubert, Y. (2016). Diversity management content model based on organisational team sport intervention. African Journal of Hospitality, Tourism and Leisure, 5 (2), ISSN: 2223-814X.

[16] Roberge, M, \& Dick, R. (2010). Recognizing the benefits of diversity: When and how does diversity increase group performance. Human Resource Management Review, 20, 295-308.

[17] Cunningham, G. (2009). The moderating effect of diversity strategy on the relationship between racial diversity and organizational performance. Journal of Applied Social Psychology, 39(6), 1445-1460.

[18] Jabbour, D., Gordono, F., \& Oliveira, J (2011). Diversity management challenges, benefits, and the role of human resource management in Brazilian organizations. Equality Diversity and Inclusion: An International Journal, 30(1), 58-74.

[19] Allen, R., Dawson, G., Wheatley, K., \& White, C. (2008). Perceived diversity and organizational performance. Employee relations, 30(1), 20-33.

[20] Choi, S., \& Rainey, H. (2010). Managing diversity in U.S. Federal Agencies: Effects of diversity and diversity management on employee perceptions of organizational performance. Public Administration Review, 109-121.

[21] Kochan, T., Bezrukova, K., Ely, R., Jackson, S., Joshi, A., Jehn, K., Leonard, J., Levine, D., \& Thomas, D., (2003). The effect of diversity on business performance. Human Resource Management, 42(1), 3-21.

[22] Saxena, A. (2014). Workforce diversity: A key to improve productivity. Procedia Economics and Finance, 11, 76-85.

[23] Busolo, E. (2017). The impact of workforce diversity on organizational performance: A case study of AAR group. Thesis for Master of Science in Organizational Development, United States International University Africa.

[24] Lu, C., Chen, S., Huang, P., \& Chen, J. (2014). Effect of diversity on human resource management and organizational performance. Journal of Business Research, 68, 857 -861.

[25] Syed, J, \& Kramar, R. (2008). What is the Australian model for managing cultural diversity? Personnel Review, 39(1), 96-115.

[26] Kreitz, P. (2007). Best practices for managing organizational diversity. Journal of Librarianship, 1-49.

[27] Richard, O. (2000). Racial diversity, business strategy, and firm performance: A resource-based view. Academy of Management Journal, 43(2), 164-177.

[28] Guillaume, Y., Dawson, J., Otaye-Ebede, L., Woods, S. \& West, M. (2017). Harnessing demographic differences in organizations: What moderates the effects of workplace diversity? Journal of Organizational Behaviour, J. Organiz. Behav, 38, 276-303.

[29] Liao, H., \& Joshi, A. (2006). Cross-level effects of workplace diversity on sales performance and pay. Academy of Management Journal, 49(3), 459-481.

[30] Alderfer, C., \& Sims, A. (2002). Diversity in organizations. Handbook of psychology, 12, 595-614.

[31] Olsen, J., \& Martins, L. (2016). Racioethnicity, community makeup, and potential employees' reactions to organizational diversity management approaches. Journal of Applied Psychology, 101(5), 657672 .

[32] Konrad, A. (2003). Special issue introduction: Defining the domain of workplace diversity scholarship. Group \& Organization Management, 28 (1), 4-17.

[33] Ensari, N., \& Miller, N. (2006). The application of the personalization model in diversity management. Group Processes \& Intergroup Relations, 9(4), 589-607.

[34] Sultana1, M., Rashid, M., Mohiuddin, M., \& Mazumder M. (2013). Cross-cultural management and organizational performance: A Content analysis perspective. International Journal of Business and Management, 8(8), ISSN 1833-3850.

[35] Podsakoff, P, Mackneazie, S. \& Lee, J. (2003). Common method baises in behavioral research: a critical review of the literature and recommended remedies. Journal of applied psychology, 88(5), 879903.

[36] Joseph, D., Jin, J., Newman, D. and O’Boyle, E. (2015). .Why Does Self-Reported Emotional Intelligence Predict Job Performance? A Meta-Analytic Investigation of Mixed EI. Journal of Applied Psychology, 100(2), 298-342. 